\title{
Activities and initiatives of the renewed European Society of Human Genetics (ESHG) (1992-2017)
}

\author{
Peter S Harper \\ European Journal of Human Genetics (2017) 25, S2-S5; doi:10.1038/ejhg.2017.141
}

This short introductory note is a continuation of the article already published in the May 2017 Special Issue of the Journal. ${ }^{1}$

The new structure of the Society and the momentum generated by this soon resulted in a number of initiatives beyond the core activity of the annual congress. Only a few of these are mentioned here (Table 1), but already their importance can be recognised in the history of development of European human and medical genetics, making the preservation of primary records important for future historians documenting this key area of science and medicine. A beginning of this is made by the recollections of many of the principal actors in the following contributions. Some of these initiatives of Table 1 arose within the Society itself, whereas others were stimulated by outside events.

\section{THE EUROPEAN JOURNAL OF HUMAN GENETICS}

Started in 1993, this new journal was one of the first initiatives of the 'renewed' Society. Initially edited by Giovanni Romeo and subsequently by Gertjan van Ommen, it provided the first clear indication that the Society was moving away from the restricted original remit of the annual meeting as its sole activity. Practical aspects of the publication were not always straightforward, however, as indicated by correspondence in the records. Published quarterly at first by Karger of Basel (who already had close links with human cytogenetics and gene mapping), it moved to Stockton Press in 1998, then already a part of 'Nature Publishing Group' and fully subsumed by it in 2000.

Table 1 The 'renewed' ESHG; some major initiatives since 1992

1993 Founding of the Society's own journal-European Journal of Human Genetics 1996 ESHG becomes part of the International Federation of Human Genetics Societies

1998 ESHG website initiated

2001-ESHG coordinated campaign against patenting of human genes

2001-Response to European Union proposals in relation to cloning and other

ethical issues

2003 Alternate year linked historical workshops (Genetics and Medicine Historical Network)

2008 Vienna-based permanent secretariat with Executive Officer (Jerome del

Picchia)

2012 European Board of Medical Genetics formed
ESHG also set up a publications committee in 2000, to ensure satisfactory communications, while an electronic version of the Journal has existed since 1999.

Apart from the publication of original articles, a valuable function of the journal has proved to be the dissemination of ESHG reports, as well as of European collaborative studies and other EU initiatives, which might otherwise have remained relatively unnoticed without formal publication.

\section{ESHG AWARDS}

An annual award, the Mauro Baschirotti award 'in recognition of individual achievements in human genetics' had already been associated with the Society since 1992 (first recipient Lore Zech), but in 2003, this was superseded by its own 'ESHG award' for lifetime achievements, followed in 2005 by the 'education award' (first recipient Giovanni Romeo) and then several 'young investigator awards', named poignantly after geneticists who had themselves died young.

\section{ESHG WEBSITE}

The initial website for the Society was set up in 1998 by Ségolène Aymé under the auspices of INSERM, the French medical research council, and extended in 1999 by Peter Farndon during his term as Secretary-general. It is now the principal source of information regarding the Society, including aspects of its history. However, websites are by their nature changeable, and much of the content of the ESHG website placed there as 'current' information will become of historical importance in the near future. It is thus essential that some form of web-archiving is undertaken if these details are not to be lost.

\section{COMMITTEES AND REPORTS}

As Jan Mohr had correctly predicted, the restructuring of ESHG soon led to the development of a number of committees (Table 2), and a series of specific reports (Table 3). Only a selection of these are mentioned in this article; whereas more detailed accounts of the recent history of the Society, will follow on after this introduction.

\section{PATENTING OF HUMAN GENES}

The 1990s saw an explosion in the identification and isolation of human genes, in particular those involved in serious genetic disorders. This was marked by intense collaboration and cooperation world- 


\section{Table 2 ESHG standing committees}

Annual Meetings Committee

Education Committee

European Board of Medical Genetics

Eurogentest Committee

Public and Professional Policy Committee

Scientific Programme Committee

Table 3 Some valuable ESHG reports

2002, 2010 Guidelines on training for genetic specialists

2009, 2013 Genetic testing in asymptomatic minors

2010 Direct to consumer testing for health-related purposes

2011 Genetic testing and common disorders

2013 Whole-genome sequencing in healthcare

wide, with most medical genetics centres across Europe involved. Even those without access to advanced molecular technology could contribute to this research by providing samples and clinical data from families, whereas new discoveries were rapidly applied to genetic diagnosis and prediction, and became incorporated into wider genetics services.

This process itself had a powerful influence on strengthening links between geneticists across Europe, and on the ESHG itself, but was challenged by proposals from the American company Myriad Genetics to restrict clinical use of the newly discovered breast cancer susceptibility gene, $B R C A 2$, which was already becoming widely used in genetic diagnosis. Even more restrictive was the company's proposal that all samples must be sent to their US laboratories for analysis.

By the time that the dangers of the situation were recognised (the first correspondence in the ESHG records is September 2001), a patent had already been granted in the US, and it was clear that an urgent and coordinated response across Europe was needed, involving the various national human genetics Societies, ESHG itself, and close liaison with the EU. Much of this coordination was undertaken by Dr Gert Matthijs (Leuven), and the largely successful eventual outcome showed the value of ESHG being able to respond rapidly and represent the whole of Europe on important issues.

\section{EU 'FIORI REPORT' AND PROPOSED LEGISLATION ON CLONING AND OTHER ETHICAL ISSUES}

Another important example of a 'reactive' ESHG initiative is its response to the EU report on ethical and legal aspects of human genetics, known as the 'Fiori report'. The initial draft of this report was a balanced assessment of the issues, but a series of last minute amendments, following intense political lobbying, introduced numerous highly restrictive proposals, including a total ban on all forms of cloning and on funding for research related to this. As with the patenting issue, this called for a rapid and coordinated response and close contacts with the EU and its agencies, the need being increased by the likelihood of the forthcoming EU 'Framework Programme' for research being seriously affected. The correspondence in the ESHG records and the response itself will, like that on patenting, be of value to future historians.
EUROPEAN SCHOOL OF MEDICAL GENETICS (LATER RENAMED EUROPEAN SCHOOL OF GENETIC MEDICINE)

This was initiated in 1988, independent of ESHG but always closely associated with it, following the Society's renewal shortly afterwards. The principal organiser from its inception was Giovanni Romeo, then at Genoa, and the venue for the first decade of the course was a magnificent (though cold!) castle at nearby Sestri Levante. The venture was modelled on the Bar Harbor 'Short Course in Medical Genetics' that had been run for many years by Victor McKusick of Johns Hopkins Hospital, Baltimore (with whom Romeo had trained), and a key factor in the success of the new course was the active involvement of McKusick himself and some of his staff. Renamed as the 'European Course in Genetic Medicine' and subsequently located at Bertinoro, near Bologna, it now forms part of an extensive educational programme under the auspices of the EU.

\section{DOCUMENTING AND PRESERVING THE HISTORY OF ESHG IN THE FUTURE}

Documenting the beginnings and the development of ESHG over its first half century, as outlined in the article in the first ESHG History special issue and this contribution, has been based on a variety of written and oral sources. For the Society's first 25 years, covering the period 1966-1991, we are fortunate that it was in effect entirely run by a single individual, Jan Mohr; that his correspondence and records were meticulously organised, and that they have been largely preserved and catalogued as a part of the wider Tage Kemp Archive, forming part of the Danish National Archive. Despite its apparent security, however, this archive was seriously neglected in recent years, and suggestions that it might be disposed of entirely were only avoided by the perseverance of one or two staff members of the Copenhagen Medical Genetics Institute. These risks now seem to have been avoided, and renewed interest, including research for the present article, has led to re-cataloguing and conservation of the entire collection, of which material relating to ESHG forms only a small part.

Records of the Society from 1992, covering a range of rapid developments following its 'renewal', and corresponding to the terms of office as Secretary-General of Professors Jean-Jacques Cassiman and Peter Farndon, have been preserved principally in Birmingham, while part of them has been digitised. Thus, there is a relatively complete collection of records over this period also. The present collection of detailed recollections by many of the principal actors is of major assistance to achieve a proper account of the growth of the ESHG in the second 25-year phase, between 1992 and 2017

However, this raises the questions of whether ESHG should now have its own long-term archive, where such an archive should be based, and whether it should be exclusively digital or also print based. If no action is taken, particularly in relation to those items existing only in digital format, it is likely that a substantial part of the documentation of the Society's recent and ongoing history will be at best widely scattered and in the worst case irrevocably lost. It would be sad if someone coming to write the centennial history of ESHG were to find that little more existed than that currently available for its first 50 years!

\section{CONFLICT OF INTEREST}

The author declares no conflict of interest. 


\section{ACKNOWLEDGEMENTS}

For the writing of this paper and the previous part concerning the period of 1967-1992, I am grateful to a number of people for their help in the preparation of this article. First, the Society itself requested it, and kindly helped with covering the costs of visiting the Copenhagen archive. The staff of the Danish National Archives, in particular Erik Kann, were exceptionally helpful in searching for and retrieving material relevant to ESHG, while the Panum Institute kindly allowed me to make a base there during my two visits. I am grateful to Professors Nils Tommerup and Ole William Petersen, successive heads of the Institute, for allowing this and especially to Dr Marie-Luise
Bisgaard for her hospitality and general help in searching the archive. Professor Peter Farndon kindly copied a considerable number of more recent ESHG documents, located at his Birmingham unit. Further valuable information on the Society came from Charles Buys, Anthony Edwards, Gertjan van Ommen and Giovanni Romeo.

1 Harper PS: The European Society of Human Genetics: beginnings, early history and development over its first 25 years. Eur J Hum Genet 2017; 25: S2-S9. 


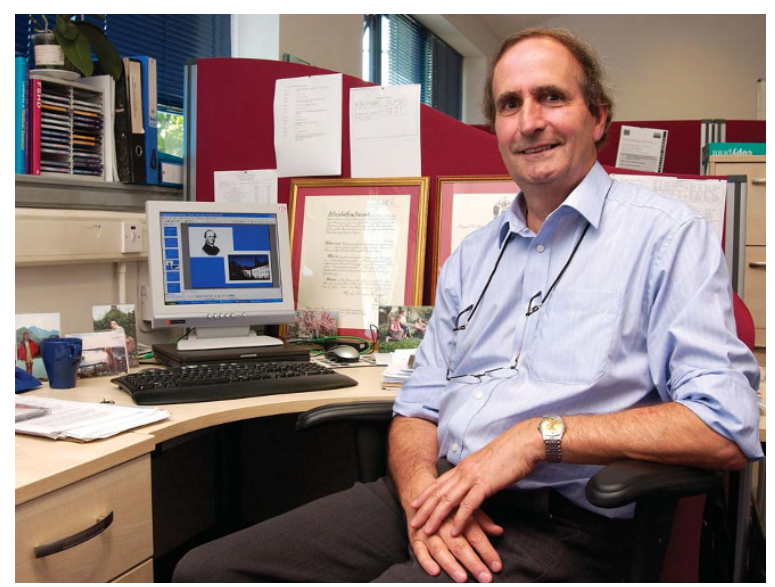

Peter Harper is Emeritus Professor of Human Genetics at Cardiff University and until 2004 was Professor of Medical Genetics and Physician at University of Wales College of Medicine, Cardiff. Previously he was educated in Medicine at Oxford University and trained in medical genetics with Cyril Clarke in Liverpool and Victor McKusick in Baltimore.

His principal research has been in the clinical and molecular genetics of neurogenetic disorders, notably myotonic dystrophy and Huntington's disease, while he has also been much involved in service, policy and ethical aspects of medical genetics. He has written the widely used and translated book 'Practical Genetic Counselling'.

Since 2002 he has been working on documenting and preserving the history of human and medical genetics across the world and was responsible for founding the 'Genetics and Medicine Historical Network', whose activities include the www.genmedhist.org website (now under the auspices of ESHG), a series of seven international workshops on Genetics, Medicine and History, the Human Genetics Historical Library, and a series of 100 interviews with founders in the field internationally, which is now being continued across Europe by ESHG.

His historical books include 'Landmarks in Medical Genetics' (2004). 'First Years of Human Chromosomes' (2006), and 'A Short History of Medical Genetics' (2008).

He has been involved with ESHG since 1969 and was its chair in 1988 at the Cardiff meeting when the reform of the Society was initiated. 